\title{
WUJUD SAPAAN “ANAK” DALAM TINDAK TUTUR BERBAHASA BANJAR
}

\section{INFRASTRUCTURES GREETINGS"CHILD" SPEECH ACTS LANGUAGE IN BANJAR}

\author{
Rissari Yayuk \\ Balai Bahasa Provinsi Kalimantan Selatan \\ Jalan A. Yani km 32,2, Loktabat, Banjarbaru, Kalimantan Selatan \\ Pos-el: yrissariyayuk@yahoo.co.id \\ Telepon 089691827674
}

\begin{abstract}
Abstrak
Judul penelitian ini adalah wujud sapaan "anak" dalam tindak tutur berbahasa Banjar. Penelitian ini dimaksudkan mendeksripsikan wujud sapaan anak dalam tindak tutur berbahasa Banjar yang selama ini belum pernah diteliti. Melalui penelitian ini akan diketahui salah satu budaya masyarakat Banjar khususnya di lingkungan keluarga. Permasalahan yang diangkat 1) Bagaimana wujud penanda sapaan anak bahasa Banjar? dan 2) Bagaimana realisasi penggunaan sapaan anak bahasa Banjar dalam tindak tutur?. Tujuan yang akan dicapai adalan untuk mengetahui 1) Wujud penanda sapaan anak bahasa Banjar dan 2) Realisasi penggunaan sapaan anak bahasa Banjar dalam tindak tutur?.Jenis penelitian ini adalah deskriptif kualitatif. Teknik yang digunakan dalam pengambilan data adalah teknik rekam dan dokumentasi. Berdasarkan hasil penelitian diketahui bahwa penanda sapaan anak dalam bahasa Banjar terdiri atas Anak atau Nak,Tung, Idang, Nang atau Anang. Keempat sapaan ini digunakan berdasarkan jenis kelaminnya dan ada yang tidak. Berikutnya, realisasi penggunaan sapaan anak bahasa Banjar dalam tindak tutur terdiri atas tindak tutur direktif, ekspresif. komisif, asertif
\end{abstract}

Kata kunci: Sapaan, tindak tutur, Banjar

\begin{abstract}
This study is intended to describe form of greeting a child in Banjar-language speech acts that have not been investigated. In fact, through this study will be known to one of the cultural community of Banjar, especially in the family environment. Issues raised 1) How marker form greeting children Banjar language? and 2) How is the realization of children's use of language Banjar greeting speech act?. Objectives to be achieved adalan to know 1) Being marker Banjar language greeting children and 2) Actual use of greeting children Banjar language in speech acts? This type of research is descriptive qualitative. Techniques used in data collection and documentation is recording technique. The study concluded Based on survey results revealed that the marker greeting child in Banjar consists of the Child or kid, Tung, Idang, Nang or Sam. Fourth greeting used by gender and there are not. Next, the realization of children's use of language Banjar greeting speech act consists of a directive speech act, expressive. commissive, assertive
\end{abstract}

Keywords: Greetings, speech acts, Banjar

\section{PENDAHULUAN}

Semua bahasa memiliki bentuk sapaan , termasuk masyarakat Banjar
Masyarakat Banjar memiliki bentuk sapaan yang bervariasi yang digunakan untuk menggantikan nama seseorang dalam 
hubungan kekerabatan sebuah keluarga, yang terdiri atas nenek, anak,dan cucu. Sapaan untuk anak yang dimiliki masyarakat Banjar sebagai tanda adanya penghormatan dan kasih sayang terhadap anak yang disapa memiliki variasi tersendiri.

Variasi bentuk kata sapaan bahasa Banjar terhadap anak sangat menarik untuk dikaji, karena menggambarkan salah satu budaya berbahasa yang terdapat dalam kehidupan keluarga masyarakat Banjar. Adapun, penelitian tentang kata sapaan secara umum pernah dilakukan Nengsih (2013) dengan judul "Variasi Panggilan dalam Tuturan Sapa Masyarakat Banjar". Akan tetapidia tidak secara umum mendeskripsikan tentang sapaan yang terdapat dalam keluarga Banjar berdasarkan situasi dan latar belakang sapaan itu digunakan.

Masalah yang akan dikaji meliputi 1) bagaimana wujud penanda sapaan anak bahasa Banjar dan 2) Bagaimana realisasi penggunaan sapaan anak bahasa Banjar dalam tindak tutur. Tujuan yang akan dicapai adalan untuk mengetahui 1) Wujud penanda sapaan anak bahasa Banjar dan 2) realisasi penggunaan sapaan anak bahasa Banjar dalam tindak tutur.

Penelitian ini dapat mendeskripsikan bentuk-bentuk sapaan khusus yang digunakan untuk menggantikan nama anak yang disapa. Diharapkan hasil penelitian ini akan memberi manfaat sebagai salah satu dokumentasi yang bisa memperkaya khazanah bahasa daerah pada umumnya.

\section{LANDASAN TEORI \\ 2.1 Sapaan}

Kridalaksana (1993:191) menyatakan bahwa semua bahasa mempunyai tutur sapa. Sapaan adalah morfem, kata atau frase yang dipergunakan untuk saling merujuk dalam situasi pembicaraan dan berbeda-beda menurut sifat hubungan antara pembicara. Chaer (2012:51-53) menyatakan kata sapaan masing-masing bahasa memiliki keunikan mengingat bahwa selain bersifat universal yakni berbagai karakteristik umum yang sama, bahasa juga memiliki sifat khas yang spesifik yang tidak dimiliki bahasa lain
Kaidah sapaan berkaitan dengan alternasi dan kookurensi. Ervin-Tripp (1972:213) menyatakan kaidah alterasi mengenai bagaimana cara menyapa yang berkaitan dengan pemilihan unsure-unsur leksikal yang disesuaikan dengan cirri-ciri orang yang disapa. Ciri-ciri ini menandai hubungan antar penutur, dan sifat situasi yang melatarbelakanginya.Kokurensi berkaitan dengan kesertaan bentuk sapaan dengan bentuk yang lainnya. Penggunaan kata-kata tersebut disesuaikan dengan situasi dan kedudukan orang yang disapa.

Biber dalam (Nengsih, 2013:54) menekankan bahwa sapaan penting untuk menjelaskan dan memellihara hubungan sosial antara partisipan di dalam percakapan. Mereka membagi sapaan menjadi delapan kategori berdasarkan penggunaannya, yaitu (1) panggilan sayang; (2) istilah kekerabatan ; (3) panggilan akrab; (4) nama akrab; (5) nama depan utuh, (6) gelar dan nama belakang; (7) sapaan hormat; dan (8) sapaan lain yang termasuk julukan.

Menurut Nengsih (2013:52) , khusus panggilan sayang dalam sebuah sapaan yang terdapat dalam masyarakat Banjar kala melakukan komunikasi ini dapat ditujukan kepada saudara, anak, orang tua, suami istri, atau orang lain di luar kerabat inti yang disayangi. Setiap sapaan dengan ragam pihak yang dituju tersebut menggunakan penandapenanda tertentu.

\subsection{Tindak Tutur}

Chaer dan Agustina (2010:64) mengkhususkan tindak tutur sebagai gejala individual, bersifat psikologis, dan keberlangsunganya ditentukan oleh kemampuan bahasa si penutur dalam menghadapi situasi tertentu. Leech dalam Jumadi (2006:115) menyebutkan tindak tutur merupakan suatu tindakan yang diungkapkan melalui bahasa yang disertai dengan gerak dan sikap anggota badan untuk mendukung maksud pembicara. Tindak tutur ditentukan oleh adanya beberapa aspek situasi ujar, antara lain (1) yang menyapa (penutur) dan yang disapa (petutur); (2) latar belakang; (3) 
tujuan sebuah tuturan; (4) bentuk tindak kegiatan; (5) produk tindak verbal.

Richards

(Suyono, 1990:5)

berpendapat mengenai tindak tutur sebagai the things we actually do when we speak " sesuatu yang benar-benar kita lakukan ketika bertutur' atau the minimal unit of speaking which can be said to have functioan ' satuan terkecil dari unit tuturan atau ujaran yang dapat dikatakan memiliki fungsi'.

Searle (1983) dalam Rustono (1999:39-43), Rahardi (2009:17), dan Ibrahim (1993:27) menyebutkan ada lima bentuk tindak tutur yang dilakukan orang sewaktu memproduksi ujaran dilihat dari fungsi ilokusinya. Pembagian Searle didasarkan bentuk tuturan dan kategori tindakan yang dilakukan oleh seseorang.

1. Tindak tutur asertif atau biasa juga disebut tindak tutur representatif adalah tindak tutur yang berkaitan dengan menyatakan sesuatu. Tindak tutur ini mengikat penuturnya akan kebenaran atas apa yang diujarkan. Bentuk tindak tutur ini biasanya dilakukan orang sewaktu dia mengemukakan pendapat/ menyatakan sesuatu, berspikulasi, mengklaim, dan melaporkan.

2. Tindak tutur direktif adalah tidak tutur yang dimaksudkan agar lawan bicara melakukan sesuatu, fungsinya seperti meminta, menyarankan, melarang, serta memerintah.

3. Tindak tutur komisif adalah jenis tindak tutur yang penuturnya berjanji untuk melakukan sesuatu, memiliki fungsi seperti berjanji, bersumpah, dsb.

4. Tindak tutur ekspresif adalah bentuk tindak tutur yang diutarakan untuk mengungkapkan perasaan penutur terhadap sesuatu keadaan, fungsinya seperti berterima kasih, memberi ucapan selarnat atau bela sungkawa, meminta maaf, menyalahkan, memuji, dsb.

\section{METODE DAN TEKNIK PENELITIAN}

Metode yang digunakan adalah
metode deskriptif. Metode ini
menggambarkan fenomena yang terjadi pada
tuturan yang ada secara empiris. Penelitian ini

dilakukan untuk mendapatkan gambaran secara alamiah. Hal ini sesuai dengan pendapat Djajasudarma (1993:54) dan Moleong (1995:68) yang mengatakan bahwa data yang digunakan hendaknya bersifat akurat dan alamiah. Jadi, data yang dihasilkan berupa deskripsi penggunaaan bahasa penuturnya secara langsung.

Data yang dikumpulkan berbentuk deskripsi percakapan penutur bahasa Banjar dalam ragam situasi dan kondisi. Pengumpulan data dilakukan dengan cara pengamatan dan perekaman. Pengamatan dan perekaman ini dilakukan untuk membuat catatan atau dokumentasi dari lapangan secara langsung atas apa yang dilihat, dialami, dan dipikirkan dari data primer. Data di ambil dari tuturan lisan masyarakat Banjar di lingkungan masyarakat Teknik yang digunakan dalam pengambilan data adalah teknik rekam, dokumentasi. dan pustaka.. Teknik ini digunakan untuk mendapatkan data lisan dan tertulis sebagai pendukung serta sumber-sumber lainnya yang berkaitan dengan tindak tutur berbahasa Banjar di arena yang sudah ditentukan

Berikutnya, teknik pengambilan sampel yaitu purposive sampling, yaitu teknik pengambilan sampel sumber data dengan pertimbangan tertentu (Sugiyono, 2009:300). Penetapan sampel tidak didasarkan keterwakilan dalam hal jumlah responden (besar sampel), tetapi berdasarkan kualitas atau ciri-ciri responden yang ingin diwakili.

Teknik analisis data yang dipergunakan adalah analisis interaktif. Analisis data dilakukan dengan langkahlangkah, pengumpulan data, indentifikasi data, klasifikasi, seleksi dan interpretasi. Langkah ini saling berhubungan dan berkelanjutan. Hasil analisis data disajikan dengan kata-kata biasa dengan terminologi yang teknis sifatnya.

Berdasarkan metode dan teknik di atas, penulis menempuh tiga langkah kerja, yaitu tahap pengumpulan data, pengolahan data, dan tahap penyajian hasil analisis data, hal ini sesuai pula dengan yang dimaksudkan Sudaryanto (2003:57) . Data yang telah dikumpulkan selanjutnya diperiksa secara 
selektif berdasarkan permasalahan yang ada, data terpilih ini dianalisis disesuaikan dengan teori pragmatik, dan disajikan dengan metode informal atau kata-kata biasa.

Populasi penelitian ini adalah masyarakat Banjar yang berlokasi di lingkungan masyarakat Kalimantan Selatan. Pengambilan data dilakukan dari tanggal Desember 2014 sampai Juni 2015. Wilayah pengambilan sampel data di Kampung Tambak, Kabupaten Banjar. Penetapan sampel tidak didasarkan keterwakilan dalam hal jumlah responden (besar sampel), tetapi berdasarkan kualitas atau ciri-ciri responden yang ingin diwakili.

\subsection{Wujud Penanda Sapaan Kesayangan Bahasa Banjar}

\subsubsection{Penanda Sapaan Anak atau Nak}

[1] A: Uh Anakku baiman, batuah jangan pang bagayaan haja, malam hudah arinya, kaluah kamarawaan

'Hai anakku yang beriman, bertuah jangan dong bercanda saja, malam sudah , nanti bisa kerasukan'

B: Hii takutaann, inggih kami kada bagayaan lagi ma aai

'Hii takut ah, iya kami tidak bercanda lagi bu'

(Konteks: dituturkan seorang ibu kepada anak-anaknya yang sedang bercanda)

Ujaran pada data [1] dituturkan oleh seorang kepada dua orang anaknya yang saat itu asik bercanda. Sementara waktu itu sudah menjelang magrib. Si ibu atau penutur membuat kalimat ujaran dengan menggunakan kata sapaan kesayangan anak'anak'. Sebagaimana dalam bahasa Indonesia, khusus makna kata dalam kalimat ujar ini berarti panggilan untuk seseorang yang memiliki garis keturunan dengan dia dan telah dilahirkannya. Penggunaan kata anak ini sebagai kata ganti dari nama anak penutur.
[2] A: Nak...nak. Ikam tuh pamasian pang wan uma, jar uma

jangan umpatatan,

jangan umpatan tuh. Han kalu

paampihannya kana minyak kalu!

'Nak...nak. Kamu itu menurut dong dengan Ibu, kata Ibu

jangan ikut, jangan ikutan .

Nah kan akhirnya kena miyak'

B: Uma ma, maksud ulun handak mandanii. Kada tahu

Sakiit Ma

pang paampihannya kaya ini.

'Aduh $\mathrm{Bu}$, maksud saya ingin

membantu. Tidak tahu akhirnya

seperti ini, Sakiit Bu'

(Konteks: dituturkan seorang ibu kepada anaknya )

Ujaran [2] dituturkan oleh seorang ibu kepada anaknya dengan lokasi tempat dapur. Dalam konteks ini, penutur mengujarkan kalimat tersebut karena sianak yang berkalikali di larang untuk ikut memasak di dapur, ternyata tetap ada di samping penutur. Akhirnya mitra tutur terkena cipratan minyak - Penggunaan Nak'nak' ditujukan penutur kepada anaknya atau mitra tutur.

\subsubsection{Penanda Sapaan Tung}

[3] A: Umaii rajinnya ikam nih tung, manyiram kambang jua sakalinya

'Aduh rajin sekali kamu Tung, menyiram kembang juga ya ternyata'

B: Inggih Niaai nah, rami daripada bamainan haja, barangai mandanii

Mama basisiram (tertawa)

- Iya Nek, asyik daripada

bermain saja, lebih baik menolong

Ibu bersiram-siram'

(Konteks: dituturkan seorang

nenek kepada cucunya yang sedang menyiram bunga di depan rumahnya)

Ujaran [3] dituturkan seorang nenek kepada cucu kesayangannya yang terlihat sedang menyirami bunga di di depan rumah. Nenek ini terlihat senang sekali menyaksikan 
cucunya yang masih kecil ternyata pandai melakukan pekerjaan orang tua. Untuk menyatakan rasa senang dan sayangnya, penutur menuturkan kalimat ujaran dengan menggunakan kata ganti Tung. Kata Tung dalam bahasa Banjar berarti 'beruntung.'

[4] A: Pinanya ikam nih makin hari makin bungas haja Tungai

'Sepertinya kamu ini semakin hari semakin cantik saja, Tung'

B: Umaai piyan nih julak ai bisa banar, asa taambung ulun nah

'Aduh Anda ini, Bibi bisa sekali, terasa tersanjung saya nah'

(Konteks: dituturkan seorang bibi kepada keponakannya yang sedang duduk di beranda rumahnya)

Data [4] diujarkan oleh seorang bibi kepada keponakannya yang terlihat bersih dan rapi. Keponakannya ini adalah salah satu anak yang disayangi penutur. Penutur memuji akan kecantikan sang keponakan yang terlihat semakin hari semakin cantik saja. Penggunaan kata ganti Tung yang artinya beruntung diucapkan oleh penutur kepada keponakannnya tersebut. Keponakannya pun menjadi tersipu-sipu.

\subsubsection{Penanda Sapaan Idang} ka mul?

[5] A: Ma jadi kalu kita bulan kaina mall?'

'Bu jadi kan kita bulan nanti ke

B: Inggih dangai, kaina kita ka mulai, tapi munnya ikam puasanya kada pacah-pacah 'Iya Dangai nanti kita ke mall, tetapi kalau kamu puasanya tidak ada yang pecah'

(Konteks: dituturkan seorang ibu kepada anaknya dalam rumah)

Data [5] dituturkan seorang ibu kepada anak perempuannya yang merengek minta ke mall bulan depan. Permintaan anaknya ini ditanggapi dengan senyuman. Penutur menjawab dengan kalimat yang di dalamnya memiliki kata sapaan kesayangan Idang. Masyarakat Banjar menggunakan kata ini biasanya untuk ditujukan kepada anak perempuan kesayangannya.

[6] A: Amun ulun rangking satu, ulun piyan barii apa Ma?

'Kalu saya juara satu, saya akan diberi apa Bu?'

satu, bujuran Mama

B: Amun ikam Dangai rangking tukarakan sapida, bujur nah Mama kada bakaramput

( Konteks: dituturkan seorang ibu kepada anaknya)

Data [6] dituturkan oleh seorang ibu kepada anaknya yang menanyakan akan diberi apa jika mitra tutur jadi juara kelas. Sang ibu atau penutur menanggapi kalimat ujar ini dengan menggunakan kalimat yang mengandung sapaan kesayangan Idang. Kata ini digunakan sebagai wujud rasa sayang penutur selaku orang tua kepada anak peremuannya.

\subsubsection{Penanda Sapaan Nang}

[7] A: Hari ini sakulahan am Nang lah, babaju hanyaram

baru dong' 'Hari ini sekolah ya, berbaju

B: Inggih Cil ai, masukan pulang am padahal asa nyaman banar

kata turun alias paraian

'Iya Bi, turun kembali ke sekolah, padahal terasa enak sudah tidak turun alias liburan

(Konteks: dituturkan oleh seorang bibi kepada keponakannya)

Data [7] dituturkan seorang bibi kepada keponakan tersayangnya. Kata sapaan ini untuk menggantikan nama panggilan anak laki-laki pada masyarakat Banjar. Penutur menyatakan pendapatnya bahwa berhubung waktu sekolah sudah tiba, berarti keponakannya ini akan memakai baju baru di tahun ajaran baru tersebut. 


\subsection{Penggunaan Sapaan dalam Tindak Tutur Bahasa Banjar \\ 4.2.1 Penggunaan Sapaan Bahasa Banjar dalam Tindak Tutur Direktif}

Tindak tutur direktif merupakan tindak tutur yang dilakukan oleh penutur agar mitra tutur melakukan apa yang telah diekspresikan penutur melalui perkataan dan tindak verbal yang mengiringinya. Tindak tutur direktif yang terdapat dalam ujaran bahasa Banjar dengan menggunakan kata sapaan kesayangan adalah terdapat pada data [1] dan [2].

Ujaran pada data [1] dituturkan oleh seorang kepada dua orang anaknya yang saat itu asik bercanda. Sementara waktu itu sudah menjelang magrib. Uh Anakku baiman, batuah jangan pang bagayaan haja, malam hudah arinya, kaluah kamarawaan 'Hai anakku yang beriman, bertuah jangan dong bercanda saja, malam sudah, nanti bisa kerasukan'. Penutur menggunakan kata sapaan anakku dalam kalimat perintahnya karena yang melakukan aktivitas tersebut adalah anak-anak kesayangannya.

Masing-masing anak ini memang memiliki nama panggilan masing-masing. Akan tetapi sudah menjadi kebiasaan masyarakat Banjar untuk lebih menekankan apa yang diucapkan kepada mitra tutur yang disayangi, maka kata ganti anakku menjadi pilihan sapaan. Sapaan ini terdapat dalam kalimat direktif larangan. Penutur melarang anak-anaknya untuk terus bercanda karena malam sudah tiba, lebih baik mengerjakan shalat dan belajar. Penanda kalimat direktif larangan yang menggunakan kata sapaan kesayangan anak ini adalah jangan pang 'jangan dong'. Frase ini digunakan agar supaya anak-anaknya ini berhenti beraktivitas yang tidak dikehendaki penutur. Hasil dari tindak tuturnya ini mendapat respon dari anak-anaknya sebagai mitra tutur. Hal ini dapat dilihat melaui ujaran mitra tutur Hii takutaann, inggih kami kada bagayaan lagi ma aai 'Hii takut ah, iya kami tidak bercanda lagi bu'

Sementara itu untuk data [2] juga menyatakan adanya penggunaan kata sapaan kesayangan anak dalam ujaran yang mengandung kalimat direktif laranngan.
Penanda kalimat larangan dapat dilihat pada ujaran penutur Nak...nak. Ikam tuh pamasian pang wan uma, jar uma jangan umpatatan, jangan umpatan tuh. Han kalu paampihannya kana minyak kalu! 'Nak...nak. Kamu itu menurut dong dengan Ibu, kata Ibu jangan ikut, jangan ikutan . Nah kan akhirnya kena miyak'.

Dalam ujaran pada data [2] sapaan nak'nak' diulang oleh penutur. Penutur mengekspresikan rasa sayang tersebut kepada anaknya dalam kondisi agak jengkel. Hal ini disebabkan berdasarkan konteks, penutur sudah beberapa kali memperingatkan kepada mitra tutur agar tidak usah membantunya di dapur karena bisa kecipratan minyak goring. Namun mitra tutur tidak mentaatinya. Di tengah kejengkelannya ini, penutur tetap menyatakan rasa sayang tersebut terhadap mitra tutur.

Untuk meredakan rasa jengkel penutur, mitra tutur tersebut memberi alasan kenapa dia ikut di dapur. Uma ma, maksud ulun handak mandanii. Kada tahu pang paampihannya kaya ini. Sakiit Ma 'Aduh $\mathrm{Bu}$, maksud saya ingin membantu. Tidak tahu akhirnya seperti ini, Sakiit Bu'.

\subsubsection{Tindak Tutur Ekspresif}

Tindak tutur ekspresif adalah sebuah tindak tutur yang digunakan untuk mengungkapkan perasaan penutur terhadap mitra tutur . Berdasarkan hasil kajian dalam penelitian ini ditemukan beberapa kalimat ujar yang mencerminkan tindak tutur ekspresif dengan menggunakan kata sapaan kesayangan. Salah satu contoh tindak tutur ini adalah terdapat pada data [3] dan [4]

Pada ujaran [3] yang dituturkan oleh seorang nenek kepada cucu kesayangannya dilakukan karena menyaksikan cucunya yang masih kecil ternyata pandai melakukan pekerjaan orang tua. : Umaii rajinnya ikam nih tung, manyiram kambang jua sakalinya 'Aduh rajin sekali kamu Tung, menyiram kembang juga ya ternyata'. Tuturan nenek tersebut mengungkapkan perasaannya terhadap apa yang telah dilakukan sang cucu atau mitra tutur. 
Tuturan ekspresif penutur mendapat tanggapan dari penutur Inggih Niaai nah, rami daripada bamainan haja, barangai mandanii Mama basisiram (tertawa)' Iya Nek, asyik daripada bermain saja, lebih baik menolongi Ibu bersiram-siram'. Artinya ungkapan ekspresif penutur yang mengandung kata sapaan kesayangan Tung telah berhasil membangkitkan emosi mitra tutur. Mitra tutr terlihat malu-malu menjawab ujaran neneknya atau penutur.

Sementara itu, pada data [4] diujarkan oleh seorang bibi kepada keponakannya.Penutur memuji akan kecantikan keponakan yang terlihat semakin hari semakin cantik saja. Pinanya ikam nih makin hari makin bungas haja Tungai 'Sepertinya kamu ini semakin hari semakin cantik saja, Tung'. Ujaran pujian yang mengandung kata sapaan kesayangan ini menunjukkan tindak tutur ekspresif dari penutur kepada mitra tutur.

Mitra tutur yang terdapat pada data [4] adalah keponakan penutur yang sering dimanjakan oleh penutur. Penutur mengekspresikan rasa sayangnya melalui ujaran memuji tersebut. Dalam ujaran memuji ini lah penggunaan Tung semakin memperkuat akan ekspresi rasa sayang penutur kepada mitra tutur.

\subsubsection{Penggunaan Sapaan Bahasa Banjar dalam Tindak Tutur Komisif}

Tindak tutur komisif dilakukan oleh penutur sebagai upaya untuk meyakinkan mitra tutur akan apa yang dia lakukan kelak. Contoh tindak tutur komisif yang memiliki ujaran sapaan kesayangan ini terdapat pada data [5] dan [6] .

Ujaran yang terdapat pada data [5] dituturkan oleh seorang ibu kepada anak perempuannya yang merengek minta ke mall bulan depan. Ma jadi kalu kita bulan kaina ka mul? 'Bu jadi kan kita bulan nanti ke mall?'. Si anak atau mitra tutur begitu memelas saat berbicara.

Penutur menjawab rengekan mitra tutur dengan lembut. Penutur pun mengeluarkan ujaran yang mengandung kata sapaan kesayangan Dangai atau Idang. Ujaran tersebut menunjukkan penutur melakukan tindak tutur komisif. Dalam peristiwa tutur ini , penutur berupaya meyakinkan mitra tutur bahwa nanti akan ke mall. Inggih dangai, kaina kita ka mulai, tapi munnya ikam puasanya kada pacah-pacah 'Iya Dangai, nanti kita ke mall, tetapi kalau kamu puasanya tidak ada yang pecah'.

Pada ujaran yang terdapat di data [6] dituturkan oleh seorang ibu kepada anaknya yang menanyakan akan diberi apa jika mitra tutur jadi juara kelas. Mitra tutur berujar Amun ulun rangking satu, ulun piyan barii apa Ma? 'Kalau saya juara satu, saya akan diberi apa Bu?'. Pertanyaan ini menghasilkan respon dari penutur.

Penutur berujar Amun ikam Dangai rangking satu, bujuran Mama tukarakan sapida, bujur nah Mama kada bakaramput 'Iya Dangai, nanti kita ke mall, tetapi kalau kamu puasanya tidak ada yang pecah'. Ujaran ini dilakukan oleh penutur sebagai upaya untuk meyakinkan mitra tutur akan apa yang dia lakukan kelak. Penutur melakukan tindak tutur komisif berjanji terhadap apa yang dijanjikannya kepada mitra tutur.

\subsubsection{Penggunaan Sapaan Bahasa Banjar dalam Tindak Tutur Asertif}

Tindak tutur asertif atau disebut pula tindak tutur repsesentatif adalah tindakan yang berkaitan dengan menyatakan sesuatu. Tindak tutur ini berlaku biasanya kala penutur mengemukakan pendapat. Contoh tindak tutur ini dapat dilihat pada data [7]

[7] A: Hari ini sakulahan am Nang lah, babaju hanyaram

baru dong'

'Hari ini sekolah ya, berbaju

B: Inggih Cil ai, masukan pulang am padahal asa nyaman banar

kata turun alias paraian

'Iya Bi, turun kembali ke

sekolah, padahal terasa enak sudah

tidak turun alias liburan

(Konteks: dituturkan oleh

seorang bibi kepada keponakannya)

Data [7] dituturkan seorang bibi kepada keponakan tersayangnya. Kata sapaan 
ini untuk menggantikan nama panggilan anak laki-laki pada masyarakat Banjar. Penutur menyatakan pendapatnya bahwa berhubung waktu sekolah sudah tiba, berarti keponakannya ini akan memakai baju baru di tahun ajaran baru tersebut. Hari ini sakulahan am Nang lah, babaju hanyaram 'Hari ini sekolah ya, berbaju baru dong'.

Ketika penutur berujar pada data [7] tersebut, Hari ini sakulahan am Nang lah, babaju hanyaram 'Hari ini sekolah ya, berbaju baru dong' dituturkan dengan lembut . Penutur menggunakan kata Nang atau Anang untuk memanggil keponakan laki-laki yang disayanginya. Anang adalah sapaan untuk menggantikan nama diri seorang anak lakilaki dalam keluarga Banjar. Berdasarkan budaya masyarakat Banjar penyebutan sapaan ini biasanya digunakan dalam rangka menunjukkan rasa sayang seseorang terhadap anak laki-lakinya.

Ungkapan sapaan penutur dijawab dengan lembut pula oleh lawan tutur. Lawan tutur memang keponakan yang sangat dekat dengan bibinya. Dia sangat senang berada di rumah bibinya tersebut kala sedang liburan. Inggih Cil ai, masukan pulang am padahal asa nyaman banar hudah kata turun alias paraian 'Iya $\mathrm{Bi}$, turun kembali ke sekolah, padahal terasa enak sudah tidak turun alias liburan

\section{PENUTUP}

Berdasarkan hasil penelitian diketahui bahwa penanda sapaan anak dalam bahasa Banjar terdiri atas Anak atau Nak,Tung, Idang, Nang atau Anang. Keempat sapaan ini digunakan berdasarkan jenis kelaminnya dan ada yang tidak. Untuk sapaan Naka atau anak dan Tung atau beruntung digunakan untuk menyapa anak-anak tanpa membedakan jenis kelaminnya. Sedangkan untuk kata sapaan Idang hanya untuk anak perempuan. Sementara sapaan untuk anak laki-laki adalah Anang.

Berikutnya, realisasi penggunaan sapaan anak bahasa Banjar dalam tindak tutur terdiri atas tindak tutur direktif, ekspresif. komisif, asertif. Penggunaan sapaan anak yang digunakan dalam tindak tutur direktif dilakukan kala untuk memerintah lawan tutur. Untuk penggunaan sapaan anak dalam tindak tutur ekspresif adalah kala penutur mengungkapkan isi hatinya terhadap apa yang terjadi pada lawan tutur, seperti memuji. Berikutnya, penggunaan sapaan komisif digunakan kala penutur untuk mengingatkan akan apa yang akan dilakukannnya kelak, seperti berjanji. Untuk tindak tutur asertif, penggunaan kata sapaan dilakukan penutur sebagai bentuk pernyataan atas apa yang dilihatnya atau sedang terjadi pada diri lawan tutur.

\section{DAFTAR PUSTAKA}

Chaer, Abdul .2012. Sosiolinguistik. Jakarta: Rineka

Chaer, Abdul dan Leonie Agustina. 2010. Sosiolinguistik: pengenalan awal. Jakarta: Balai Pustaka

Djjasudarma, T. Fatimah 1993. Metode Linguistik; Ancangan Metode Penelitian dan Kajian. Bandung. PT Eresco

Ervin-Tripp Susan M. 1972. On Sociolinguistic Rules: Alternation and Co- occurannce Rules dalam Directions in Sociolinguistics suntingan John J. Gumperz dan Dell Hymes: 213-250. New York: Holt and Winston. Inc.

Ibrahim, Abdul Syukur. 1993. Kajian Tindak Tutur. Surabaya: Usaha Nasional

Jumadi.2006. Representasi Kekuasaan. Jakarta. Pusat Bahasa.

Kridalaksana, Harimurti. 1993.Pragmatik. Jakarta: Gramedia.

Moleong, L. J. 1995. Metodologi Penelitian Kualitatif. Bandung: Remaja Rosdakarya

Nengsih, Sri Wahyau. 2013. Variasi Panggilan dalam Tuturan Sapa Masyarakat Banjar. Bunga Rampai Bahasa. 46-79. Banjarbaru: Balai Bahasa Provinsi Kalimantan Selatan

Rahardi, R. Kunjana. 2005/2009. Pragmatik. Jakarta:Erlangga

Rohmadi, Muhammad. 2004. Pragmatik Teori dan Analisis. Yogyakarta: Lingkar Media Jogja 
Rustono. 1999. Pokok-Pokok Pragmatik. Semarang: CV IKIP Semarang Press.

Sudaryanto. 2003. Metode dan Aneka Teknik Analisis Bahasa: Pengantar Penelitian Wahana
Kebudayaan
Linguistis. Yogyakarta: Duta Wacana University Press.

Sugiyono. 2009. Metode Penelitian. Bandung: Alfabeta

Suyono. 1990. Pragmatik: Dasar-Dasar dan Pengajaran. $\quad$ Malang: YA3. 